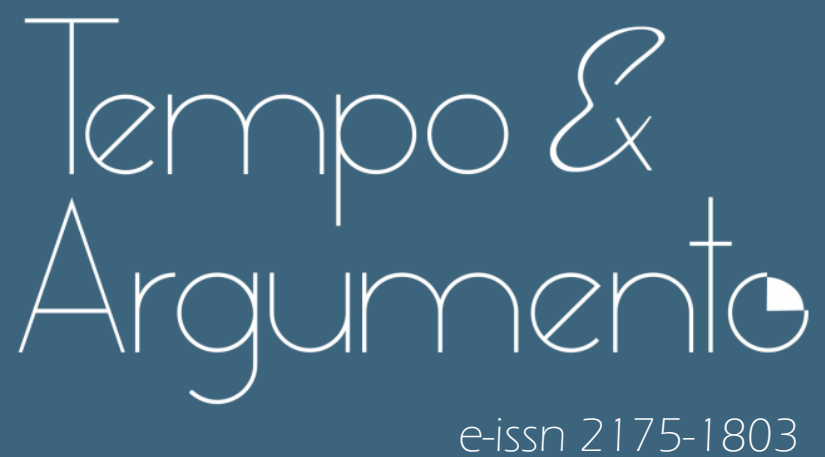

\title{
O avanço neoconservador antigênero na América Latina durante o século XXI
}

Resenha da obra:

BIROLI, Flavia; VAGGIONE, Juan Marco; MACHADO, Maria das Dores Campos Machado. Gênero, Neoconservadorismo e Democracia: Disputas e Retrocessos na América Latina. São Paulo: Boitempo, 2020.

- Eloisa Rosalen

Doutoranda em História na Universidade Federal de Santa Catarina (UFSC).

Florianópolis, SC - BRASIL lattes.cnpq.br/3857428948780807

rosaleneloisa@gmail.com

(D) orcid.org/0000-0001-5125-9969

Para citar esta resenha:

BIROLI, Flavia; VAGGIONE, Juan Marco; MACHADO, Maria das Dores Campos Machado. Gênero, Neoconservadorismo e Democracia: Disputas e Retrocessos na América Latina. São Paulo: Boitempo, 2020. Resenha de: ROSALEN, Eloisa. 0 avanço neoconservador antigênero na América Latina durante o século XXI. Revista Tempo e Argumento, Florianópolis, v. 13, n. 32, e0401. jan./abr. 2021. http://dx.doi.org/10.5965/2175180313322021e0401 


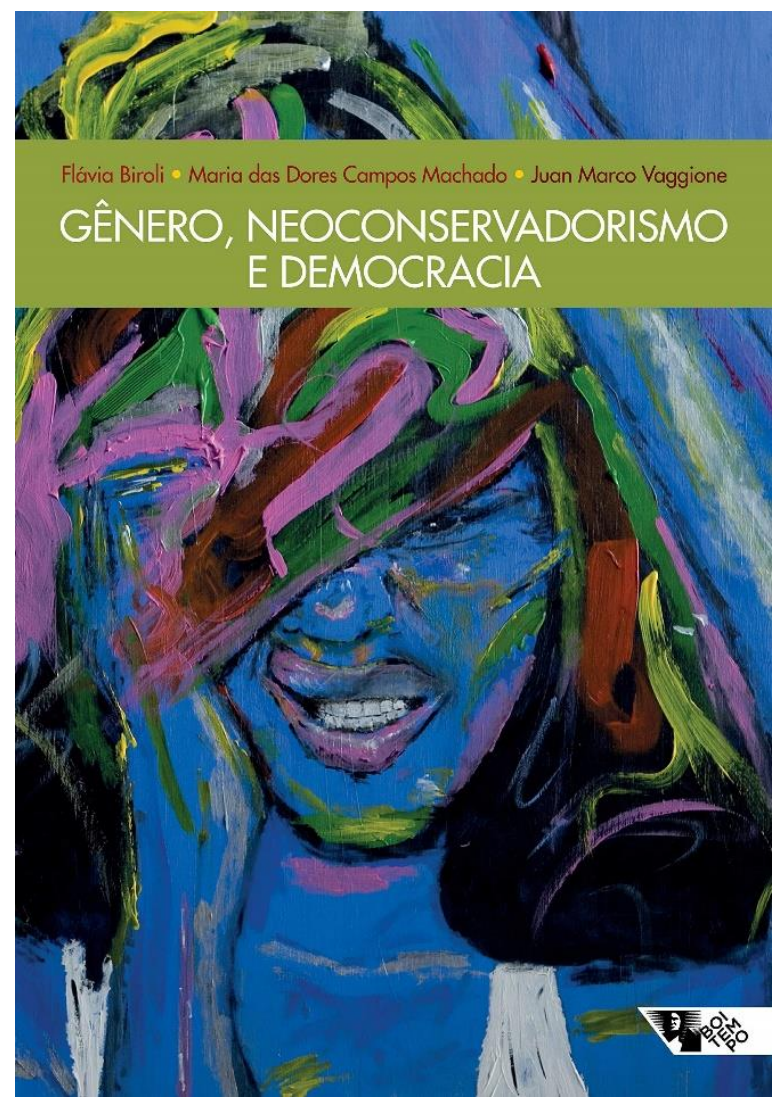

\section{Resenha da obra:}

BIROLI, Flavia; VAGGIONE, Juan Marco; MACHADO, Maria das Dores Campos Machado. Gênero, Neoconservadorismo e Democracia: Disputas e Retrocessos na América Latina. São Paulo: Boitempo, 2020.

O livro Gênero, Neoconservadorismo e Democracia: Disputas e Retrocessos na América Latina, organizado e escrito por Flávia Biroli, Juan Marco Vaggione e Maria das Dores Campos de Machado, publicado no ano de 2020 pela Editora Boitempo, analisa o crescimento do neoconservadorismo no que tange aos direitos sexuais e reprodutivos, à educação voltada ao gênero e sexualidade, aos estudos de gênero e aos direitos humanos. Sobretudo, o objetivo do livro, como identificado nas primeiras páginas, é de entender o avanço neoconservador em relação ao gênero a partir de uma perspectiva interdisciplinar, transnacional e comparativa ao relacioná-lo com os debates que envolvem religião, direitos e democracia (BIROLI; VAGGIONE; MACHADO, 2020). O livro traz um debate significativo ao mobilizar as disputas e discussões políticas atreladas à "ideologia de gênero", à "cultura da morte" e à igualdade de gênero que tomou corpo nas últimas duas décadas do século XXI na América Latina.

Já faz algumas décadas que as autoras e o autor do livro têm se dedicado às pesquisas que envolvem gênero, política e religião. Como poder ser visto, Flávia Biroli é professora e pesquisadora no Instituto de Ciência Política da Universidade de Brasília (UnB), onde tem realizado inúmeras publicações, e tem se dedicado às temáticas da democracia, política, estudos de gênero e teoria feminista no Brasil contemporâneo. Já, Juan Marco Vaggione é doutor em direito pela Universidade Nacional de Córdoba (UNC), na Argentina, e em sociologia pela 
New School for Social Research, nos Estados Unidos. Atualmente, é professor titular de sociologia da Faculdade de Direito da UNC e pesquisador do Consejo Nacional de Investigaciones Científicas y Tecnicas (Conicet) da Argentina; também dirige o Programa de Direitos Sexuais e Reprodutivos da Faculdade de Direito da UNC. Por sua vez, Maria das Dores Campos de Machado é doutora em Sociologia pelo Instituto Universitário de Pesquisas do Rio de Janeiro e tem se dedicado aos estudos das religiões, neoconservadorismo e à política brasileira. Atualmente, é professora aposentada e voluntária na Universidade Federal do Rio de Janeiro.

A soma das diferentes trajetórias de pesquisas e análises acaba dando destaque à obra resenhada aqui. A análise está centrada na emergência do neoconservadorismo e no avanço sobre a democracia ao inter-relacionar os ataques ao gênero no contexto atual; aspecto, este, considerado muitas vezes menor nas principais produções que hoje se voltam a pensar a democracia na América Latina. Para analisar o fenômeno, Flávia Biroli, Juan Marco Vaggione e Maria das Dores Campos de Machado (2020) propõem cinco dimensões, a fim de identificar as características contemporâneas do neoconservadorismo: 1o) "O conceito de neoconservadorismos permite jogar luz sobre as alianças e afinidades entre diferentes setores" (BIROLI; VAGGIONE; MACHADO, 2020, p. 28); 2) a expressiva utilização da juridificação da moralidade; $3^{\circ}$ ) o fato de que o neoconservadorismo opera em contexto democrático, ao mesmo tempo em que o fere; $4^{\circ}$ ) o caráter global e transnacional (adicionado aqui por mim) do neoconservadorismo do século XXI; 5) a relação entre neoconservadorismo e a agenda neoliberal no que tange aos direitos das mulheres e dos sujeitos LGBTQI.

O livro foi dividido em três capítulos, em que foram abordadas as seguintes temáticas: as reações dos atores religiosos (católicos ou evangélicos), as tentativas de restrição das agendas ligadas à igualdade de gênero, as disputas entre os movimentos feministas e LGBTQI e os movimentos conservadores; o transnacionalismo dos avanços das agendas conservadoras na América Latina, os ataques políticos em diferentes esferas institucionais (jurídicos, parlamentar, etc.) aos poucos avanços nas últimas décadas que envolveram a igualdade de gênero; a interconexão entre o avanço conservador com as políticas neoliberais, 
a mobilização dos direitos humanos como argumento para participação e defesa dos projetos conservadores, a centralidade da família como uma tendência transnacional no projeto político neoconservador, os padrões do neoconservadorismo religioso, o caráter novo do conservadorismo que emerge no século XXI e a aliança entre distintos setores nas agendas antigênero (BIROLI; VAGGIONE; MACHADO, 2020).

No primeiro capítulo, intitulado A restauração legal: o neoconservadorismo e o direito na América Latina, escrito por Juan Marco Vaggione, o objetivo foi compreender como "O neoconservadorismo se instalou como um problema complexo para a reflexão analítica e normativa" (BIROLI; VAGGIONE; MACHADO, 2020, p. 42). Mais precisamente, por meio do conceito de "juridificação reativa”", o autor se dedicou a entender como se deu (por meio de quais sujeitos e de que maneira) o crescente "movimento de restauração moral por meio do direito" (BIROLI; VAGGIONE; MACHADO, 2020, p. 42). Em outras palavras, foi pensado como o direito vem sendo instrumentalizado para a defesa dos princípios morais neoconservadores na ofensiva contra o gênero. O capítulo é denso, cheio de exemplos e discussões que envolvem os direitos sexuais e reprodutivos das últimas décadas na América Latina e esteve pautado na ideia de que a juridificação reativa seria tanto uma arena quando uma estratégia para o avanço neoconservador (BIROLI; VAGGIONE; MACHADO, 2020).

Já, no capítulo de Maria das Dores Campos Machado, com o título 0 neoconservadorismo cristão no Brasil e na Colômbia, o aspecto central foi a comparação entre os dois países que compõem o título no que diz respeito à emergência neoconservadora dos grupos cristãos. O capítulo traça um panorama ao abordar questões ligadas ao ensino, religião, projetos de leis, crescimento de percentuais religiosos, avanço do conservadorismo entre os anos de 2014 até 2018, o papel das ONG's religiosas para a interversão no debate público, entre outros aspectos. Também sublinhou, graças à circulação dos líderes religiosos, sobre a propagação dos valores e da agenda antigênero, a construção de redes e eventos transnacionais e como as novas tecnologias facilitaram na promoção

\footnotetext{
Juridificação reativa é o termo utilizado para designar o uso do direito por parte dos atores neoconservadores para a defesa dos seus princípios morais e para avançar na disputa contra o gênero (BIROLI; VAGGIONE; MACHADO, 2020).
} 
de agendas que desafiam a democracia (BIROLI; VAGGIONE; MACHADO, 2020). O grande destaque do capítulo refere-se à autora ter chamado a atenção para a atuação das mulheres conservadoras (seja como deputadas, pastoras ou ministras) na agenda antigênero, contra os debates sobre os direitos sexuais e reprodutivos, na desqualificação do feminismo e em defesa da moral cristã.

Na tentativa de entender a relação entre gênero e democracia, Flávia Biroli, no capítulo Gênero, "valores familiares" e democracia, analisou "os processos de transformação das democracias no mesmo contexto em que as disputas em torno do gênero ganham novos padrões" (BIROLI; VAGGIONE; MACHADO, 2020, p. 136). A autora foca na discussão dos estudos que vêm se indagando sobre a desdemocratização e como o gênero vem sendo considerado nas análises; a relação entre as evidências empíricas no combate ao gênero, principalmente, os valores democráticos e a maneira como se dá a contestação dos estudos de gênero na qualidade de área científica e acadêmica (BIROLI; VAGGIONE; MACHADO, 2020).

Os aspectos mais interessantes do capítulo tratam de demarcar as ideias que constituem os argumentos dos grupos neoconservadores, de que os lobbies feministas e LGBTQI ameaçam as crianças e a família, que as organizações internacionais têm como objetivo subjugar a nação por meio do enfraquecimento da família, que as crianças precisam ser protegidas dentro das autoridades reconhecidas, a família, e que os movimentos de minorias ameaçam as maiorias agindo contra a democracia (BIROLI; VAGGIONE; MACHADO, 2020). Por isso, o sentido de democracia está em disputa no tempo presente e precisa ser debatido.

As discussões propostas no livro tiveram como base dois grandes marcos conceituais (apresentados na introdução): o neoconservadorismo e a temporalidade. Foi com o segundo eixo que tive certo incômodo, uma vez que sua construção se deu ao tentar verificar as políticas antigênero. As autoras e o autor falam em "uma nova temporalidade" a partir das ameaças ao gênero, pautadas em termos como “ideologia de gênero". No entanto, o tempo parece compacto em um grande bloco único, o que me faz questionar: não seriam múltiplas (no plural) temporalidades na América Latina? Em todos os países da 
América Latina, as ameaças se deram da mesma maneira e nos mesmos marcos temporais? Conforme foi sendo demostrado ao longo dos capítulos, ocorreram trânsitos, projetos, avanços e derrotas que não foram lineares e homogêneos em todos os países. Sem falar que o avanço neoconservador não tomou corpo em todos os países e já vendo sofrendo limitações. Em outras palavras, as temporalidades foram muito diversas e ainda precisam ser mais bem exploradas. Por último aqui, os avanços neoconservadores estão alinhados ao negacionismo enfrentado, de uma maneira geral, em diferentes âmbitos, como, aqueles ligados às ciências e às universidades; pouco citado em suas multiplicidades no livro.

O Livro Gênero, Neoconservadorismo e Democracia é uma leitura precisa ao dar historicidade aos embates políticos presentes na América Latina do século XXI. Mobiliza diferentes disciplinas para a análise dos segmentos sociais, culturais e econômicos, que fizeram com que disputas e conservadorismo tomassem corpo e significado durante o período. O tema é extremamente atual, pertinente e importante, tanto para pesquisadores quanto para quem busca entender como se manifestou o avanço neoconservador nas últimas duas décadas. Por isso, o livro é importante a fim de entendermos mais sobre a história do tempo presente no que tange ao neoconservadorismo, às ameaças à igualdade de gênero e às democracias na América Latina. Também significa uma análise do quão complexo e novo são esses movimentos e os desafios que têm sido enfrentados pelos diferentes movimentos sociais, ativistas e pesquisadores, com os avanços das agendas antigênero. Como sinalizou Flávia Biroli, "há mais em jogo do que visões de mundo conflituosas" (BIROLI; VAGGIONE; MACHADO, 2020, p. 185); entender, historicizar e analisar o que acontece (como foi feito neste livro) é valoroso para quem se interessa pela história do tempo presente.

Universidade do Estado de Santa Catarina - UDESC

Programa de Pós-Graduação em História - PPGH Revista Tempo e Argumento Volume 13 - Número 32 - Ano 2021 tempoeargumento@gmail.com 